\title{
Ecolalia de Luís Quintais: para uma proposta de tradução como procura do esquecimento
}

\author{
Gaia Bertoneri*
}

\begin{abstract}
Resumo
No presente artigo, pretendemos analisar a obra do poeta português contemporâneo Luís Quintais a partir da nossa própria experiência de tradução do português para o italiano da antologia poética Ecolalia, publicada em Itália pela editora LietoColle, em 2018, como tentativa de investigação da mesma. O tema que põe em relação a obra do autor com a estrutura da antologia italiana é a memória. Em primeiro lugar, apresentaremos a obra de Luís Quintais através de alguns poemas incluídos na antologia mencionada. Em segundo lugar, tentaremos aplicar à nossa reflexão sobre o trabalho de tradução aquilo que Walter Benjamin chamava processo de «reativação do eco do original» (BENJAMIN, 2008, p. 52) para observar como o esquecimento se torna importante para estudar a obra do poeta português. Estudaremos essa peculiaridade tentando nos questionar sobre o sentido de 'ecolalia' debatido por Heller-Roazen (HELLER-ROAZEN, 2007), linguista e tradutor, evidenciando o papel da memória nos sujeitos afásicos. Por último, demonstraremos como a memória se revela eficaz quer na atividade de tradutores profissionais quer na nossa proposta de tradução do português para o italiano.
\end{abstract}

Palavras-chave: Poesia Portuguesa Contemporânea. Luís Quintais. Tradução. Memória. Esquecimento.

\footnotetext{
* Universidade de Turim (Itália). Doutora em Digital Humanities-Literatura portuguesa contemporânea (Universidades de Génova e Turim), professora de Língua Portuguesa na Universidade de Turim. https://orcid.org/0000-0001-7676-2421.
} 


\title{
Ecolalia by Luís Quintais: for a Translation Proposal as a search for oblivion
}

\author{
Gaia Bertoneri
}

\begin{abstract}
In this article, we intend to analyze the work of the contemporary Portuguese poet Luís Quintais from our own experience of translating from Portuguese into Italian the poetic anthology Ecolalia, published in Italy by LietoColle in 2018 , as an attempt to investigate it. The theme that relates the author's work with the structure of the Italian anthology is memory. First, we will present the work of Luís Quintais through some poems included in the mentioned anthology. Secondly, we will try to apply to our reflection on the work of translation what Walter Benjamin called the process of «reactivation of the echo of the original» (BENJAMIN, 2008, p. 52) to demonstrate how forgetting becomes important to study the work of the Portuguese poet. We will study this aspect trying to question ourselves about the meaning of 'echolalia' debated by the linguist and translator Heller-Roazen, highlighting the role of memory in aphasic subjects. Finally, we will demonstrate how memory is effective both in the activity of professional translators and in our translation proposal from Portuguese into Italian.
\end{abstract}

Keywords: Contemporary Portuguese poetry. Luís Quintais. Translation. Memory. Oblivion. 
Tra un fiore colto e l'altro donato

l'inesprimibile nulla.

Giuseppe Ungaretti

O objetivo do nosso artigo é apresentar o projeto de tradução do português para italiano do volume poético Ecolalia de Luís Quintais publicado pela editora LietoColle de Como, em 2018, na coletânea "Gialla Oro", no âmbito do Festival literário Pordenonelegge, ocorrido na Itália, em Setembro de 2018. Para tal, primeiro, apresentaremos como o trabalho de tradução se poderia definir 'cópia', no sentido benjaminiano, do processo criativo do autor que faz da memória o lugar de abrigo e, ao mesmo tempo, de perturbação. Secundariamente, estudaremos como esta não só se torna elemento fundamental na interpretação da obra do poeta, bem como caracteriza a própria atividade de tradução. Na nossa análise, o texto de partida voltará a ser pensado como análise segunda de outro texto que já não é aquele de chegada porque "a tradução transplanta, assim, o original para um domínio linguístico que, nesta medida - e ironicamente -, é mais definitivo, uma vez que não poderá ser deslocado daí por mais nenhuma tradução" (BENJAMIN, 2008, p. 90). Trata-se de um percurso em busca do "verso antigo" de Luís Quintais que revisita os momentos mais importantes da obra do autor.

Passaram dez anos entre a nossa intenção e aquela de António Fournier, organizador da antologia e divulgador da obra de Quintais na Itália, para poder concretizar o projeto de tradução aqui apresentado. $\mathrm{O}$ volume em questão nos permitiu dar a conhecer a obra de um poeta português quase desconhecido num contexto sociocultural italiano de relevo como o festival literário Pordenonelegge. Por isso, foi importante escolher poemas nos quais se apresentam os temas mais marcantes da obra do autor. Luís Quintais foi, juntamente com os poetas italianos Franco Buffoni, Valerio Magrelli e a poeta estadunidense Martha Serpas, o escritor convidado para participar na ocasião do lançamento da antologia. A antologia poética foi apresentada juntamente com a presença do autor e do editor. O volume foi estruturado com a intenção de recriar a versão original tendo em conta o que Walter Benjamin afirma no seu texto $A$ tarefa do tradutor: "A tradução é uma forma. Para a apreender enquanto tal, é necessário regressar ao original, pois nele

Ecolalia de Luís Quintais: para uma proposta de tradução como procura do 136 esquecimento 
reside a lei da tradução, contida na sua tradutibilidade (Übersetzbarkeit)" (BENJAMIN, 2008, p.83). De modo particular, tentaremos examinar a relação entre aquilo de que nos lembramos e o de que nos esquecemos. Para demonstrar como o esquecimento é uma procura constante em tradução, nos parece oportuno começar por apresentar, sinteticamente, a obra de Luís Quintais e, particularmente, observar que a memória é um tema central na obra do autor e, como introduzimos, foi o elemento marcante de que nos servimos para estruturar o nosso projeto de tradução do português para o italiano.

Luís Quintais é um dos poetas mais conceituados no âmbito da poesia portuguesa contemporânea. A sua obra, resultado de quase trinta anos de carreira, está composta por: A imprecisa melancolia (1995), Lamento (1999), Umbria (1999), Verso antigo (2001), Angst (2002), Duelo (2004), Canto onde (2006), Mais espesso que a água (2008), Riscava a palavra tor no quadro negro (2010), Depois da música (2013), O vidro (2014), Arrancar penas a um canto de cisne. Poesia 2015-1995. (2015), A noite imóvel (2017), Agon (2018) e Ângulo Morto (2021). Quintais publicou também os livros Deus é um lugar ameaçado (2018) e Regressarás à leveza do ver. Uma viagem no Japão. (2020) que testemunham o diálogo entre dois interesses do autor, isto é, a escrita e a fotografia. O poeta começa a sua carreira literária em 1995, e, desde o seu início, foi considerado pela crítica uma das vozes mais originais da sua geração. Assim o poeta Gastão Cruz o define: "Noutros mundos se moveu, desde o começo, a poesia de Luís Quintais [...] A [sua] poesia procura uma interpretação para o mundo, reflete sobre 'a importância misteriosa de existir' de que falava Pessoa" (CRUZ, 2008, p. 372). A sua obra foi traduzida para castelhano, francês, inglês, alemão, croata e húngaro. Obteve os mais importantes prêmios literários (o PEN Clube Português, o Prêmio Fundação Luís Miguel Nava, o Prêmio Fundação Inês de Castro, o Prêmio António Ramos Rosa, o Prêmio Associação Portuguesa de Escritores (Teixeira de Pascoaes, Prêmio Correntes de Escritas) a começar pelo seu primeiro livro que foi publicado graças à atribuição do Prêmio Aula de Poesia de Barcelona. A poesia de Luís Quintais é caracterizada pela melancolia e é profundamente marcada por tons sombrios e elegíacos como podemos observar nos versos do poema "Da dificuldade da beleza": "Penso em Ungaretti nas trincheiras / recordando os seus rios: o Isonzo, o Nilo, etc. / Há uma fuga nesta indiferença. / São nobres os exemplos / e 
exemplar a responsabilidade do alheamento./” (QUINTAIS, 2015, p. 763). A sua profissão de antropólogo o tornou ainda mais atento à perceção da realidade que existe na linguagem: não se acha um pessimista, mas um "cético encantado" e um "pensador lírico" (QUINTAIS, 2019). Esta autodefinição está motivada pelo seu olhar lúcido sobre o mundo, nos lembremos do poema "Centauro": "Declinas os nomes das paisagens:/ árvore, fogo, matéria, fetos, lava./ Há em ti uma torção de estratos/ que antigos gramáticos não surpreenderam./" (QUINTAIS, 2015, p. 514). Quintais considera que o tom emocional dos seus textos reflete um tipo de escrita meditativa e reconhece que o mérito de escrever está em conseguir falar da própria natureza da linguagem, tornando manifesta assim aquela que chamamos "realidade" (QUINTAIS, 2019), pensemos no poema "Abrirás uma porta, escutarás a emudecida imagem": "Abrirás uma porta, escutarás a emudecida imagem,/ e versos mover-se-ão no sangue, em sobressalto, /e velozes medos, alicerçados em ecos,/ dirão a contragosto o que recusaste, o lixo/" (QUINTAIS, 2015, p. 221). Dado que é um grande admirador dos clássicos da literatura mundial, as suas referências são infinitas bem como a sua curiosidade de leitor.

Os versos de Luís Quintais não revivem só dos poetas do Passado como Homero, Virgílio, Luís de Camões, Dante Alighieri, mas convocam também autores como Marcel Proust, James Joyce, Yukio Mishima, J.G. Ballard, ou seja, Quintais não é só um atento apreciador da poesia, mas é também um leitor onívoro de ficção. Para ele, os melhores poetas portugueses da segunda metade do século XX são Herberto Helder, Fiama Hasse Brandão, António Franco Alexandre e nota-se uma peculiar inspiração na poesia de Daniel Faria, pensemos no livro Deus é um lugar ameaçado (QUINTAIS, 2018) que parece evocar Homens que são como lugares mal situados (FARIA, 2016), no qual, como afirma Maria João Cantinho, os seres humanos a que se refere Daniel Faria são "vítimas modernas de uma alienação da experiência, que encontra o seu correlato na experiência da desintegração da linguagem, da sua perda" (CANTINHO, 2016). Quintais se apresenta como um poeta que escreve em português, mas viajante por outras culturas literárias. Quais são então os “mundos” poéticos que adora? São Emily Dickinson, T. S. Eliot, William Butler Yeats, Dylan Thomas, só para citarmos alguns. O seu Mestre é Wallace Stevens, cujo The man with the blue guitar e outros poemas traduziu para o português. Ao reconhecer na poesia a forma mais verdadeira para falar da linguagem, o poeta acrescenta

Ecolalia de Luís Quintais: para uma proposta de tradução como procura do 138 esquecimento 
seu interesse pelas potencialidades da tecnologia, especialmente enfatizamos que a sua intensa curiosidade se tem focado na relação entre ciência e arte; um exemplo desse interesse o percebemos no poema "Rumor": "Um dia disse-te / que o rumor da ciência / é a poesia./” (QUINTAIS, 2017, p. 159). $\mathrm{A}$ arte, em todas as suas formas, resiste à usura do tempo e, para dizer com as palavras do poeta, "o poema ocorre quando a realidade se suspende, sob efeito de uma ausência que ele explicita, dando lugar à imaginação e aos seus sortilégios" (QUINTAIS, 2015, p. 8), isto é, aquele momento mágico que a escrita pode tornar eterno. Essa é uma das muitas peculiaridades o que possibilita que, na obra mencionada, a memória adquira um papel central: se trata da "linguagem crepuscolar da memória", verso do conhecido poema "Azagaia, árvore, sombra" (QUINTAIS, 2017, p. 755) de A imprecisa melancolia (1995), o primeiro livro do autor, no qual o poeta "faz viajar no eterno" (QUINTAIS, 2017, p. 755) "uma azagaia pendurada na parede" (QUINTAIS, 2017, p. 755). Graças à memória, os “ecos” parecem reverberar ao longo da sua obra, como se pode ver nos seguintes versos de "Terra sigillata": "O sonho da linguagem despertal o misterioso espelho do que passa." (Lamento, 1999); de "Degrau": "vou lacerando o papel onde escrevo/ a memória, o líquido teatro/ onde o pensamento se faz distância,/ margem e morte.//" (Canto onde, 2006); de "An Italy of the mind": "Na Itália da mentel não sabemos/ se é de noitel ou se é de dia./” (A noite imóvel, 2017). $\mathrm{Na}$ nota introdutória ao volume Arrancar penas a um canto de cisne. Poesia 2005-1995, Quintais afirma:

Porém, não gosto de dizer que [os poemas] estão do lado do som. Prefiro a ideia de eco. O som terá acontecido, e o mundo - na sua materialidade de que a linguagem faz parte - devolve-me o som. O som da minha voz? Da corrente de consciência que em mim circula como um vento que espalha aquilo que sou? Os poemas não são vetoriais, são escalares [...] Estou a falar da inescapável condição que se prende com o dado de eu não poder fazer outra coisa senão interrogar, não o início, como disse, mas um princípio de ordem. Não impressões de ordem, mas ideias de ordem [...] Assim, a atmosfera, que é um escalar - como o "medo" ou Angst que quis convocar - armadilha-me a vida, e eu respondo, devolvo o seu eco, transfiguro a poderosa - e invencível - cilada. (QuinTAIs, 2015, p. 11) 
Provavelmente a 'ideia' de ordem de que nos fala o autor se revela como possível maneira de interpretar e atribuir sentido ao nosso mundo sem contar com um início, mas sim com um recomeço, ou seja, pensar que no regresso ao começar de novo o eco perdura e viaja no tempo. Ao ler o obra de Quintais percebemos que, entre nós e o mundo, há sempre um conflito por se fazer - sugerido constantemente pelos títulos dos seus livros, Angst, Duelo, Agon, Ângulo Morto - para a linguagem nos voltar a oferecer a possibilidade de tentar fixar a realidade. Portanto a obra está sujeita a um processo de revisitação constante, como podemos ler nos seguintes versos: "Tudo é matéria de crença e revisitação" e ainda, "Tudo é revisitação nessa caixa escura” (QUINTAIS, 2015, p. 220). É nessa ótica que podemos compreender o sentido de eco proposto por Luís Quintais, isto é, uma reverberação de algo que se reconstrói in the making. Na sua antologia Arrancar penas a um canto de cisne. Poesia 2015-1995, que reúne 20 anos de poesia, o título sugere o retorno do tempo poético mais recente àquele mais remoto. O escritor se inspira a um clássico da literatura francesa, $\grave{A}$ la recherche $d u$ temps perdu, de Marcel Proust. Como na obra francesa, a antologia portuguesa é fortemente marcada pelo Tempo e pela Memória. Uma escolha criativa que é também uma escolha de vida: privilegiar o raciocínio e recusar a superficialidade nas suas várias declinações. O papel fundamental da memória volta a ser expresso pelo próprio poeta num discurso escrito para a atribuição do Prémio PEN para a Poesia que lhe foi atribuído com a publicação de O Vidro (Assírio \& Alvim, 2015) e que se pode consultar no blogue de escritor:

Não professo nenhuma estética, mas acredito no poder da memória porque é nela que se abastece todo o trabalho criativo. A minha poesia é, assim, uma arte da memória que sabe que a origem é improvável, que tudo é, em última análise, ficção e ficção retrospectiva.

A origem é improvável, disse. Talvez ela esteja comprometida com a história evolutiva da espécie, sendo que a poesia reclama uma propriedade criativa que é anterior à literatura. (QUINTAIS, 2015).

Ecolalia de Luís Quintais: para uma proposta de tradução como procura do 140 esquecimento 
Parece que os ecos sirvam de 'pano de fundo' à poesia de Quintais revelando, retrospectivamente, o seu olhar poético; essa peculiaridade volta a ser evidenciada pelo poeta numa entrevista: "todo o sentido é retrospectivo e tem a ver com algo que nos escapou [...] Sou poeta só quando olho retrospectivamente, mas não sou totalmente seguro". (QUINTAIS, 2018). Para o autor, o Tempo realiza a função da Memória que é indissociável da História. Como lemos no posfácio à edição italiana de Ecolalia, Quintais é "um supérstite do pesadelo da História recente porque viveu a condição de retournado" (FOURNIER, 2018, p. 151). Se por um lado o leitor italiano não tem uma ideia clara do que o Salazarismo, as guerras coloniais e as suas consequências representaram para Portugal, por outro é evidente que as palavras do organizador da antologia italiana nos dão um elemento importantíssimo para a compreensão de O Vidro (QUINTAIS, 2015) em que o escritor regressa à memória da sua infância em Angola, como podemos ler no primeiro fragmento poético do livro [Como chegámos a este lugar?]:

Como chegámos a este lugar? A guerra deflagrava em todas as regiões deste mapa que nos iria desenhar, a nós, ponto a ponto, semelhança a semelhança. Famílias reuniam bagagens, despediam criados, fugiam apavoradas por estradas tomadas de assalto pela vegetação densa. Impropriedade do medo, negras margens do remorso. Rompiam-se sacos placentários, criaturas atiradas para a rua do semregresso berravam a sua inviolável linguagem, precipitavam-se de encontro ao muro denso da história, exigiam um nome, um símbolo apodrecendo na eleição de um cacifo, uma caixa onde depositariam a sua fragmentada posse, o seu saque. (QUINTAIS, 2015, p. 71)

No poema citado, se torna evidente como a guerra colonial marcou profundamente a personalidade do autor e a sua obra. Pensemos também no poema "Teratologia ou na morte de J.M. Savimbi (1934-2002)" (QUINTAIS, 2015 , p. 556) que nos conta a morte do chefe da UNITA assassinado pelos seus inimigos. Os acontecimentos históricos catastróficos não passam indiferentes a Luís Quintais, vejamos, por exemplo, os versos "Foi aqui, nesta pequena cidade do atlântico sul,/ onde aprendi a dura morte./" de "Swakopmund" (Verso Antigo, 2001) ou ainda "Haverá uma opacidade 
em cada rosto/ no eterno contemplando a ofensa,/ um sulco na geleogia inteira do sem-perdão./ de "Babi Yar" (Depois da Música, 2013). É quase impossível estudar a obra de Luís Quintais sem considerar a importância de não esquecer das atrocidades do mundo e das inquietações humanas. Essa foi uma das peculiaridades que nos ajudou a estruturar o projeto de tradução da antologia italiana Ecolalia. A organização do volume mantém a estrutura da obra Arrancar penas a um canto de cisne. Poesia 2015-1995, isto é, como o título sugere, os poemas foram escolhidos a partir do livro mais recente do autor, que, em 2018, tratava-se de A Noite Imóvel ${ }^{1}$ publicado em 2017, àquele mais antigo, portanto uma estrutura em retrospectiva que em Arrancar penas a um canto de cisne começa com O Vidro, publicado em 2015, até chegar a A Imprecisa Melancolia de 1995. A seleção poética para a tradução italiana, que apresenta o texto de partida e o texto de chegada, foi organizada incluindo também alguns poemas de A Noite Imóvel (como "Asma", "Um príncipe em todas as coisas", "Lucio Fontana", "Síntese e Remorso", "Móbile" e "An Italy of the mind"). Passamos agora a refletir sobre o que significa reproduzir "o eco do original" de que nos fala Walter Benjamin e como tentamos o fazer através do nosso projeto de tradução.

Como evidencia a tradutora francesa Josée Kamoun "um tradutor não traduz palavras, frases, traduz efeitos"2 (KAMOUN, 2018). Falar da própria experiência de tradução significa investigar exatamente aqueles próprios 'efeitos' da atividade, ou seja, significa revisitar as fases a partir do momento da leitura feita com vista à tradução. Mas o que significa traduzir o efeito? No conhecido ensaio "A Filosofia da composição", ao explicar a invenção do poema "The Raven”, Edgar Allan Poe afirma: "eu prefiro começar por considerar um efeito” (POE, 2004, p. 34), ou seja, ter em conta uma série de variantes de um determinado acontecimento que realizem, da melhor maneira, os efeitos desejados despertando o eco do original. Para Poe, a composição é estruturada pela intelectualização do sentimento, ou como dizia Fernando Pessoa "o que em mim sente está pensando". Curiosamente, "The Raven” foi traduzido por Fernando Pessoa cujo trabalho foi rigorosamente analisado por Manuel Portela ${ }^{3}$ com o

\footnotetext{
1 Agon foi publicado em Outubro de 2018 ao passo que a antologia italiana Ecolalia foi publicada em Setembro do mesmo ano.

2 "Un traducteur ne traduit pas des mots, il ne traduit pas des phrases, il traduit des effets" (KAMOUN, 2018).

3 Ver https://eg.uc.pt/handle/10316/23869
}

Ecolalia de Luís Quintais: para uma proposta de tradução como procura do 142 esquecimento 
objetivo de demonstrar que traduzir significa "descobrir os princípios de composição do texto e testá-los num outro conjunto de correlações somsentido. Traduzir tomaria a forma de uma metacomposição, isto é, um segundo acto de composição que se desenvolve por referência explícita a um primeiro acto de composição" (PORTELA, 2010, p. 43). Deste modo, no texto traduzido se poderia observar o método de composição do original que se configura "de acordo com o modo de querer dizer desse original" (BENJAMIN, 2008, p. 94). Parece pertinente afirmar que o ensaio de Poe não serve de referência só a quem se dedica à atividade de escrita, mas acaba por ser um texto de grande valor também para quem se aplica ao trabalho de tradução.

Uma das figuras de referência no âmbito da Tradução, na Itália, é Susanna Basso que, na sua recolha de ensaios "Sul tradurre"(BASSO, 2010), enfatiza que traduzir implica se livrar de algo que surge nas mãos da qualidade de tradutores, e considera esta atividade como ato último, ou seja, Susanna Basso não faz mais que enaltecer o pensamento de Benjamin: ao aspirar à captação da cópia do original, o objetivo de quem traduz é concretizar um último e definitivo ato de trabalho criativo na linguagem. Sabemos também que ao cumprir a tarefa enunciada por Benjamin, a memória faz com que o tradutor cumpra uma segunda tarefa: resistir às próprias resistências. Como sabemos, a tradução é um processo dialético entre memória e luto que se concretiza na margem dupla de uma dupla resistência (RICOEUR, 2005, p. 12). Entender o que acontece entre as fases da memória e o esquecimento no processo de escrita é, para nós, de grande relevância não só para entender a temática da memória cara ao autor como já evidenciámos, mas nos serve também para realizarmos aquele ato criativo último, embora objetivamente provisório, na linguagem que, como afirma Benjamin, define a tarefa do tradutor. É importante lembrar que a análise aqui apresentada não tem o objetivo de refletir sobre problemas específicos de tradução, mas é nossa intenção oferecer uma leitura interpretativa da obra em questão de que servimos para a atividade de tradução pretendendo tentar reproduzir o eco do texto original. Se escrever poemas pode ser entendido como o ato que se concretiza a partir da própria língua materna (HELLER-ROAZEN, 2007, p. 151), que se define no espaço em que cada língua, movida pela 
música, ultrapassa os seus limites, traduzindo-se a si mesma para passar para outra língua, então é possível achar que a tradução é um processo que advém da mesma forma: poderíamos dizer que passar de uma língua para outra significa ultrapassar os limites, pessoais e circunstanciais, provocados pelo reverberar de um som em constante transformação. Isto pode ser entendido também como maneira de visitar sequências mnemônicas à procura da voz. Eis que o eco de que nos fala Quintais se verifica tanto na expressão da língua, do modo como nos sugere também Heller-Roazen, como na tentativa de reprodução para outra língua, isto é, na tradução. A memória se torna a deriva por atravessar, a procura constante que se baseia na superação de um limite. A tal propósito, Luís Quintais, fazendo referência à obra do poeta Rui Duarte Carvalho, afirma que: "A linguagem é, e eficazmente, o melhor utensílio de "extracção - fiel e verdadeira - de um mundo" [...] A palavra 'extracção' [...] é, sob este aspecto, decisiva, 'mostrar' (extraindo) um mundo, fazer com que a linguagem se dobre a ele, e não o contrário." (QUINTAIS, 2000, p. 366). O jogo poético se torna assim um conjunto das memórias semântica e acidental. Como sabemos, pensar a tradução a partir da própria experiência tradutiva significa também voltar a estudar a linguagem. Acaba por ser particularmente interessante analisar a obra do nosso poeta através dos poemas escolhidos, e acima citados, com vista à tradução evidenciando o papel da memória no sentido de 'ecolalia'. A tal propósito, vale a pena referir o poema "Ecolalia" que aqui copiamos juntamente com a nossa tradução em italiano (QUINTAIS, 2018, p. 69):

Ecolalia de Luís Quintais: para uma proposta de tradução como procura do 144 esquecimento 


\begin{tabular}{|c|c|}
\hline Ecolalia & Ecolalia \\
\hline Uma fúria secular faz-me fugir & Una furia secolare mi fa scappare \\
\hline das múltiplas vozes & dalle molteplici voci \\
\hline de um só deus. & di un solo dio. \\
\hline Está repleto de vestígios & È colmo di vestigia \\
\hline este mundo, de ecos & questo mondo, di echi \\
\hline que antepassados esclarecem & chiamati in modo equivoco \\
\hline equivocamente. & da antenati. \\
\hline O indeterminado ofício & L'indeterminato mestiere \\
\hline destes ecos repete-se & di questi echi si ripete \\
\hline $\begin{array}{l}\text { sem que eu pressinta o padrão, } \\
\text { o desarme e a nitidez. }\end{array}$ & $\begin{array}{l}\text { senza che io intuisca il modello, } \\
\text { il disarmo e la nitidezza. }\end{array}$ \\
\hline Vi o meu pai chorar, & Vidi mio padre piangere, \\
\hline e o que me vence desde aí & e ciò che mi sconfigge fin da quel momento \\
\hline é o eco do seu choro & è l'eco del suo pianto \\
\hline repetindo-se nos versos lidos, & riecheggiando nei versi letti, \\
\hline roubados por vocação sem medida: & rubati per vocazione a dismisura: \\
\hline uma janela abre-se para a pobre noite & una finestra si spalanca verso la povera notte \\
\hline da carne tomada de assalto pela linguagem. & della carne presa d'assalto dal linguaggio. \\
\hline Vejo o meu pai através dessa janela. & Vedo mio padre attraverso quella finestra. \\
\hline A linguagem inventada dilacera-me. & Il linguaggio inventato mi dilania. \\
\hline É uma música do passado, & È una musica del passato, \\
\hline uma marca d’água & un segno d'acqua \\
\hline no meu sistema nervoso. & nel mio sistema nervoso. \\
\hline Os significados são exteriores ao círculo & I significati sono esterni al circolo \\
\hline que me inclui. & che mi include. \\
\hline Persigo-os, porém. & Eppure, li inseguo. \\
\hline
\end{tabular}


Como podemos interpretar este poema? E como o podemos compreender e associar à atividade de tradução? Como sabemos, em âmbito médico, a ecolalia é considerada como um distúrbio afásico da linguagem, que se apresenta na infância, e que consiste basicamente na repetição involuntária de palavras ou frases pronunciadas por outras pessoas. Poderíamos dizer que a ecolalia convocada no poema de Luís Quintais lhe permite voltar a refletir sobre a fragilidade da expressão humana e a dificuldade da sua própria manifestação. Na ecolalia se releva que o ato de esquecer adquire um papel ativo. Quando o esquecimento de um sujeito afásico parece intencional, podemos pensar quanto o seu objeto tenha sido realmente esquecido e não o contrário, isto é, voluntariamente preservado no seu apagamento aparente. Perguntamo-nos: pode acontecer a mesma coisa ao tradutor? O balbucio de um afásico pode ser comparado à hesitação na tradução? Parece-nos importante evidenciar que o estudioso Daniel Heller-Roazen, que é também tradutor de Giorgio Agamben do italiano para o inglês, tem proposto um debate importante sobre a relação entre Filosofia e Poesia, nomeadamente sobre o esquecimento. No ensaio intitolado Ecolalie. Saggio sull'oblio delle lingue (2007), Heller-Roazen faz referência à conhecida investigação de Roman Jakobson, apresentada em Linguaggio infantile e afasia (2006). O investigador propõe a sua reflexão a partir da análise de Jakobson que, lembremos, acredita que uma criança consegue com facilidade juntar inúmeras articulações que nenhuma língua em particular possui. Heller-Roazen se foca nas capacidades da memória e do esquecimento na relação entre oralidade e escrita para compreender como é possível se esquecer dessa capacidade que se verifica na passagem da fase pré-linguística àquela de aprendizagem de uma língua. O estudioso canadense afirma o seguinte:

É como se a adquisição da linguagem fosse possível apenas através de um ato de esquecimento, uma espécie de amnésia linguística infantil (o amnésia fónica, porque o que o infante parece esquecer não é a linguagem, mas uma capacidade aparentemente infinita de articulação indiferenciada) [...] Dois acontecimentos ocorrem pelo menos na voz esvaziada pelos sons que a criança já não sabe emitir: pelo desaparecimento do balbucio eis surgir uma língua e um ser falante [...] Fica, se calhar, na linguagem do adulto algo do infinitamente variegado balbucio pelo qual surgiu? Se fosse assim, seria apenas um eco, pois onde há uma língua o

Ecolalia de Luís Quintais: para uma proposta de tradução como procura do 146 esquecimento 
balbucio infantil desapareceu há muito tempo, pelo menos na forma que tinha na boca da criança ainda incapaz de falar. Seria só um eco de outra língua, e de algo de diferente da linguagem: uma ecolalia, garante da memória daquele balbucio indistinto e imemorável que, ao se perder, permitiu existir a todas as línguas. ${ }^{4}$ (Heller-Roazen, 2007, pp. 12-3)

Na linha do que nos diz Heller-Roazen, nos parece apropriado estabelecer uma relação entre a Ecolalia, de Luís Quintais, e as fases de memória e esquecimento que, como afirma Agamben, se verificam na língua da poesia e que, para a tradutora italiana Susanna Basso, se destacam na atividade de tradução. Ao falar da sua própria experiência profissional, Susanna Basso no seu ensaio Lição de lentidão não só afirma que, com a experiência, o tradutor não acelera os ritmos, mas cura a própria impaciência (BASSO, 2010), evidenciando que falar da memória em tradução significa falar daquilo de que nós próprios esquecemos. Vejamos o que a tradutora afirma:

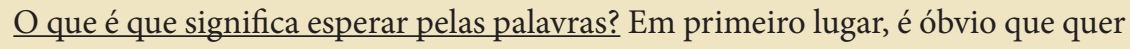
dizer não ter pressa para identificar correspondências. Mas significa também ter confiança num mecanismo de memória especial, capaz de nos fazer lembrar de algo que, pessoalmente, não sabemos [...] A memória nos pode acompanhar para a escolha certa, ou, pelo menos, nos faz perceber aquela errada. Às vezes, ao reler uma frase traduzida, não reparo em algo que não soa bem, mas me lembro disso. Traduzir é um pouco como ter romances inteiros na ponta da língua e, portanto, saber que a sensação se assemelha a uma forma de harmonia atormentadora onde a única memória certa é aquela de que nos esquecemos. .5 (BAsso, 2010, p. 7).

\footnotetext{
4 [N. d. T.] Na impossibilidade de consultar a versão original nos servimos da tradução italiana do ensaio: "È come se lacquisizione del linguaggio fosse possibile solo attraverso un atto di oblio, una sorta di amnesia linguistica infantile (o amnesia fonica, dato che ciò che l'infante sembra dimenticare non è il linguaggio, ma una capacità apparentemente infinita di articolazione indifferenziata) [...] Due fatti per lo meno avvengono nella voce svuotata dai suoni che il bambino non sa più emettere: dalla scomparsa del balbettio ecco emergere una lingua e un essere parlante [...] Rimane forse nei linguaggi dell’adulto qualcosa dell'infinitamente variegato balbettio da cui sono emersi? Se così fosse, sarebbe soltanto un’eco, poiché, dove cè una língua, il balbettio infantile è da tempo scomparso, almeno nella forma che aveva nella bocca del bambino ancora incapace di parlare. Sarebbe solo uneco di unaltra lingua, e di qualcosa d'altro dal linguaggio: unecolalia, custode della memoria di quel balbettio indistinto e immemoriale che, perdendosi, ha permesso a tutte le lingue di esistere".

5 [N. d. T.] Sublinhado nosso: "Che cosa significa dunque aspettare le parole? Innanzi tutto, è ovvio, non avere fretta di individuare corrispondenze. Ma anche fidarsi di un meccanismo speciale della memoria, in grado di farci ricordare qualcosa che, personalmente, non conosciamo [...] La memoria può da lontano guidarci alla scelta più giusta, o, se non altro, farci percepire quella sbagliata. A volte rileggo una frase tradotta e, più che accorgermi di qualcosa $\underline{\text { che non funziona, me lo ricordo. Tradurre è un po' come avere interi romanzi sulla punta della lingua, e perciò sapere che la sensazione assomiglia a una }}$ forma tormentosa di amnesia nella quale l'unico ricordo certo è che si è dimenticato".
} 
Assim a tradutora evidencia um aspecto importante no trabalho de memória: sem o esquecimento o tradutor não poderia chegar à escolha que julga certa na fase de recomposição do texto original. Se Susanna Basso levanta uma questão interessante que pode ser associada à importância do esquecimento na obra de Luís Quintais, por sua vez Giorgio Agamben nos fala do esquecimento como aspecto que caracteriza a língua da poesia:

Prefiro acreditar que a língua da poesia é o indestrutível que permanece, fica e resiste a qualquer manipulação e corrupção, a linguagem que permanece mesmo após o uso que fazemos dela [...] Acredito que a língua da poesia, a língua que permanece e chama, chama precisamente por aquilo que se perde. Vocês sabem que, tão na individualidade quanto na coletividade, o conjunto das coisas que se perdem, os acontecimentos impercetíveis de que nos esquecemos todos os dias, é tão exterminado que nenhum arquivo e nenhuma memória os poderiam conter. O que resta, aquela parte da língua e da vida que salvamos da ruína, só faz sentido se tiver intimamente a ver com aquilo que perdemos, se o chama por nome e responde em seu nome. A língua da poesia, a língua que nos fica é-nos preciosa, porque chama o que perdemos. ${ }^{6}$ (AGAMBEN, 2017).

No processo de análise da obra de Luís Quintais, ou seja, na leitura com vista à tradução (e também depois de termos traduzido), nos pareceu regressar, mais vezes, ao objeto da reminiscenza (rememoração) como o tradutor volta ao objeto esquecido. Esquecer mesmo aquilo de que nos lembramos bem significa fortalecer a memória de maneira que o esquecido se torne fatalmente autodestrutivo: quanto mais é construtivo o esquecimento, mais a memória procura o fim no próprio mutismo e o ato de esquecer nos leva involuntária e obsessivamente à palavra. Como sabemos, os sujeitos ecolálicos não se esquecem da incapacidade deles de falar de um tempo, mas se lembram da maneira deles serem incapazes. Por exemplo, o cérebro ecolálico do jovem esquizofrénico "reformula sinteticamente, sem cura, as feridas provocadas nele pelos sons de uma língua que não se parece

\footnotetext{
6 [N. d. T.] "Credo piuttosto che la lingua della poesia sia l'indistruttibile che resta e resiste a ogni manipolazione e a ogni corruzione, la lingua che resta anche dopo l'uso che ne facciamo [...] Io credo che la lingua della poesia, la lingua che resta e chiama, chiama proprio ciò che si perde. Voi sapete che, tanto nella vita individuale che in quella collettiva, la massa delle cose che si perdono, lo scialo degli infimi, impercettibili eventi che ogni giorno dimentichiamo è così sterminato che nessun archivio e nessuna memoria potrebbero contenerli. Quello che resta, quella parte della lingua e della vita che salviamo dalla rovina ha senso solo se ha intimamente a che fare col perduto, se sta in qualche modo per esso, se lo chiama per nome e risponde in suo nome. La lingua della poesia, la lingua che resta ci è cara e preziosa, perché chiama ciò che si perde."
} 
com outra"7 (ROAZEN, 2007, p. 161). Heller-Roazen nos parece sugerir um processo mnemônico de alguma coisa que por si se apresenta pouco existente. Portanto nos perguntamos: é possível interpretar a poesia de Quintais como testemunho do eco mental? Pensemos nos poemas "Mente" (Uma coisa-movimento, / assim, ao abrir a porta, e dentro / a música de a lembrar. // (QUINTAIS, 2015, p. 239) e "Memória" (Falo-te através da pura memória, / ou antes, da pura violência / de um gesto sepultado em mim./) (QUINTAIS, 2015, p. 582) que poderíamos definir exemplos da reprodução de um único som antigo que percorre a memória e que se compreende na sua solidão, que atravessa tempo e espaço e no reverberar dele se torna mais nítido. Poderíamos afirmar que a poesia de Luís Quintais provoca um 'efeito de desorientação' temporal, ou seja, a sua poesia faz perder o norte ao leitor porque propõe diferentes planos que se sobrepõem refletindo passado, presente e futuro. Essa sobreposição parece se destacar na poesia de Quintais por meio da repetição do tema memória/esquecimento como acontece no sujeito ecolálico que reproduz os sons que ouve. É como se a intenção do autor fosse preservar um tempo mental além do contexto convocado ou sugerido. Naquele tempo imóvel, acontece a chegada da imagem poética. É um tempo sobreposto que tende para a suspensão, e a lentidão se torna a mais eficaz mensagem na poética em questão. $\mathrm{O}$ que prende a mensagem à realidade é a expressão, ou seja, a linguagem. Algo que em uma determinada forma encontra o idêntico significado numa expressão diferente. $\mathrm{Na}$ construção dele próprio se reconstrói constantemente. O processo criativo de Quintais não nos lembra apenas as palavras de Susanna Basso acima citadas, mas também aquelas da tradutora Margaret Sayers Peden que apresenta uma das mais belas metáforas da tradução. Ao falar da atividade de tradução do espanhol para o inglês, Margaret Sayers Penden escreve:

Gosto de pensar a obra como um cubo de gelo. Durante o processo de tradução, o cubo se derrete. Enquanto no seu estado líquido, cada molécula muda de lugar; nenhuma permanece na sua relação original com as outras. Em seguida, começa o processo de formação da obra numa segunda língua. As moléculas escapam, são despejadas para preencher os espaços, mas as linhas de moldagem e remendo são virtualmente invisíveis. A obra sai na segunda língua como um cubo diferente, mas aparentemente igual. ${ }^{8}$ (SAYERS PENDEN, 1989, p. 13).

\footnotetext{
7 [N. d. T.] "ricapitola, senza guarirne, le ferite a lui inflitte dai suoni di una lingua che non assomiglia a nessun'altra".

8 “[N. d. T.] "I like to think of the original work as an ice cube. During the process of translation the cube is melted. While in its liquid state, every molecule changes place; none remains in its original relationship to the others. Then begins the process of forming the work in a second language. Molecules
} 
Se para Walter Benjamin o original e a tradução são vistos como duas metades para serem reunidas, lembremos a metáfora dos cacos quebrados de um vaso que o tradutor tem de colar marcando assim a fissura e demonstrando que o encaixe perfeito já não é possível, Margaret Sayers Penden evidencia o lado 'modelável' da tradução. No caso da tradutora americana, não se trata de pensar a tradução como destinada a desaparecer ao longo de um processo de mudança da língua do texto original para a língua do texto traduzido, o que está em questão é o que poderíamos chamar de plasma-invisibilidade que não envolve só a atividade de tradução em si, mas está relacionada também com o papel do tradutor. Aspecto que volta a ser evidenciado também por Simon Leys num ensaio sobre tradução literária no qual o crítico afirma que o êxito do tradutor está na sua invisibilidade, e é nessa invisibilidade que o tradutor ganha. Assim demonstra o seu grande ponto de força: o tradutor chega a conhecer a obra mais do que o próprio autor. Todas as definições, as metáforas sobre a tradução que referimos ao longo da nossa análise tentam ir ao encontro da reprodução de efeitos, isto é, aspiram a reproduzir alguns dos ecos que captámos na nossa reflexão graças à nossa própria proposta de tradução.

Podemos afirmar, para concluir, que a poesia de Luís Quintais procura constantemente tender para a memória. Não se trata de regressar a um núcleo inicial, mas de convocar um princípio de origem. Como dizia Wallace Stevens, mestre de Quintais, a poesia regressa sempre ao seu lado mais sombrio, porque ela fala das dificuldades do visível. Assim como o poeta afirma "a poesia, acontece no delta do rio, no seu movimento perpétuo, é uma cosmologia in the making" (QUINTAIS, 2015, p. 8), ou seja, é graças à ecolalia que ela própria se torna eterna. E é também graças à nossa tradução italiana que queríamos evocar, em virtude de um esquecimento voluntário, o processo de composição de Luís Quintais. A presente análise nos permitiu não só aprofundar a importância da memória e do esquecimento na obra do autor, mas nos serviu também para considerar ambos elementos-chave de uma forma outra de tradução. Através da tradução da antologia poética italiana de Luís Quintais, quisemos manter o que Walter Benjamin chama 'eco do texto original'. Pretendemos, como afirma Agamben voltar a acordar algo que ficou esquecido e que chamou por nós, algo que houvemos de salvar.

escape, new molecules are poured in to fill the spaces, but the lines of molding and mending are virtually invisible. The work exits in the second language as a cube - different, but to all appearances the same". (SAYERS PEDEN, 1989, p. 13) 
Foi nossa intenção preservar a memória do texto original na tradução, isto é, preservar o jogo constante de eco após eco. Se por um lado traduzir significa recriar ou transpor com originalidade, por outro podemos afirmar que os esforços do verdadeiro tradutor pertencem ao esquecimento ou a alguém, que virá depois dele, outro criador que na qualidade de tradutor, criará uma nova sombra. Dado que o poeta parece manipular a escrita através daquela que pode ser considerada 'memória em retrospectiva', para traduzir a sua obra tínhamos de voltar a percorrer uma viagem mental para uma cópiaeco - nos lembremos das palavras do poeta acima citadas - uma viagem não para um lugar, mas para um som que se repete ao infinito e na sua repetição torna-se de novo possível. Podemos concluir dizendo que fazemos nossas as palavras de Walter Benjamin quando acredita no trabalho de recomposição na tradução como uma tentativa de resistir às resistências da memória, e para nós, isto significa também acreditar que o esquecimento é o ato mais eficaz que a tradução nos oferece.

\section{Referências}

AGAMBEN, Giorgio. Che cosa resta?. Notas da intervenção do autor no Festival do Livro de Turim a 20 de Maio de 2017. Disponível em: https:// www.quodlibet.it/giorgio-agamben-che-cosa-resta . Accesso em: 3 Maio 2021.

BENJAMIN, Walter. A tarefa do tradutor. Tradução de João Barrento. Lisboa: Universidade Nova de Lisboa. 2008. http://escritoriodolivro.com. br/bibliografia/Benjamin.pdf Acesso em: 25 Agosto 2021.

BASSO, Susanna. Sul tradurre. Esperienze e divagazioni militanti. Milano: Mondadori. 2010.

CANTINHO, Maria João. Daniel Faria ou a (Im)possibilidade da arqueologia da palavra. Em: Revista Caliban. 15 Dez. 2016. https://revistacaliban.net/ homens-que-são-como-lugares-mal-situados-homens-que-são-comocasas-saqueadas-que-são-como-s\%C3\%ADtios-dfd35c5dc6f9 Acesso em: 15 Jun 2021. 
CRUZ, Gastão. A vida da poesia: textos críticos reunidos (1964-2008). Lisboa: Assírio\&Alvim. 2008.

FOURNIER, António. Ecolalia ovvero il grand canyon della poesia. In: Ecolalia. QUINTAIS, Luís. Como:Lietocolle. 2018. Pp. 151-155.

HELLER-ROAZEN, Daniel. Ecolalie. Saggio sull'obio delle lingue. Macerata: Quodlibet. 2007.

JAKOBSON, Roman. Linguaggio infantile e afasia. Torino: Einaudi. 2006.

KAMOUN, Josée. Entretien réalisé avec Josée Kamoun (traductrice) à loccasion de la nouvelle traduction de 1984 de George Orwell. Paris: Gallimard. Disponível em: http://www.gallimard.fr/Media/Gallimard/ Entretien-ecrit/Entretien-Josee-Kamoun.-Traduction-de-1984/ (source)/302352 . Accesso em: 5 Maio 2021.

LEYS, Simon. The experience of literary translation. In: The hall of uselessness. Collected essays. New York: New York Review Books. 2011. Pp. 245-259.

POE, Edgar Allan. A Filosofia da composição. In: Poética (textos teóricos). Lisboa: Fundação Calouste Gulbenkian. 2004. Pp. 29-52.

PORTELA, Manuel. O “Corvo” de Pessoa. Uma Filosofia da Tradução. Comunicação apresentada no colóquio "Homenagem a Edgar Allan Poe," Núcleo de Estudos do Modernismo em Língua Portuguesa, Universidade Fernando Pessoa, 10-11 de Dez. 2009. Revista da Faculdade de Ciências Humanas e Sociais, no 7, p. 40-53 (2010). Disponível em: https://eg.uc.pt/ handle/10316/23869. Accesso em: 12 Fev. 2021.

QUINTAIS, Luís. Ruy Duarte Carvalho ou a poética da identidade. In: Paisagem tipográfica. Homenagem a João Cabral de Melo Neto (19201999). Colóquio/Letras. N. 157/158. Pp. 362-7.

QUINTAIS, Luís. Entrevista à ISECTV. 2018. Disponível em: https:// luisquintaisweb.wordpress.com/bio/. Accesso em: 4 Fev. 2021.

QUINTAIS, Luís. Ecolalia. (org.) FOURNIER, António. Como: Lietocolle. 2018. 
QUINTAIS, Luís. A noite imóvel. Lisboa: Assírio\&Alvim. 2016.

QUINTAIS, Luís. Sobre «O vidro». Texto escrito por ocasião da atribuição do Prémio Pen (Poesia). Publicado a 5 de Dezembro de 2015. Disponível em: https://luisquintaisweb.wordpress.com/tag/luis-quintais/ Accesso em: 15 Mar. 2021

QUINTAIS, Luís. Wallace Stevens. O Homem da Guitarra Azul \& Outros Poemas. Lisboa: Edições Guilhotina. 2015.

QUINTAIS, Luís. Arrancar penas a um canto de cisne: poesia 2015-1995. Lisboa: Assírio\&Alvim. 2015.

RICOEUR, Paul. Temps et récit. Le temps raconté. Paris: Éditions du Seuil. 1985.

RICOEUR, Paul. Sobre a Tradução. Lisboa: Edições Cotovia. 2005.

SAYERS PEDEN, Margaret. Building a Translation, the Reconstruction Business: poem 145 of Sor Juana Inés de la Cruz. In: The craft of Translation. Edited by John Biguenet and Rainer Schulte. Chicago: The University Chicago Press. p. 13-27. 